ISSN 0103-9954

\title{
CARACTERÍSTICAS DO SOLO NA RESTAURAÇÃO DE ÁREAS DEGRADADAS NA RESERVA BIOLÓGICA DE POÇO DAS ANTAS, RJ ${ }^{1}$
}

\author{
SOIL CHARACTERISTICS IN DEGRADED AREA RESTORATION AT RESERVA BIOLÓGICA DE \\ POÇO DAS ANTAS, RJ
}

\author{
Luiz Fernando Duarte de Moraes $^{2}$ Eduardo Francia de Carneiro Campello ${ }^{3}$ \\ Marcos Gervasio Pereira ${ }^{4}$ Arcângelo Loss ${ }^{5}$
}

\section{RESUMO}

O primeiro passo para garantir o sucesso da restauração de uma área degradada é restabelecer as taxas de ciclagem de nutrientes e os níveis de matéria orgânica no solo. Para avaliar as alterações no solo em áreas sob restauração na Reserva Biológica de Poço das Antas, foram coletadas amostras em áreas de floresta madura, plantios mistos de espécies arbóreas nativas com 8 anos de vida e pastagens abandonadas, nas várzeas e morrotes. $\mathrm{O}$ delineamento experimental foi o inteiramente casualizado. As amostras foram coletadas nas profundidades de 0-2,5 cm; 2-5-7,5 cm; e 7,5-20 cm, sendo avaliados o $\mathrm{pH}$ do solo e os teores de $\mathrm{Al}, \mathrm{Ca}+\mathrm{Mg}, \mathrm{P}, \mathrm{K}, \mathrm{C}$ e $\mathrm{N}$ do solo. Os plantios da várzea apresentaram teores de $\mathrm{Ca}+\mathrm{Mg}, \mathrm{K}, \mathrm{C}$ e matéria orgânica do solo (MOS) superiores aos dos outros tratamentos, indicando o rápido estabelecimento de altas taxas de ciclagem de nutrientes e alta taxa de atividade biológica. Os valores das bases trocáveis foram mais altos para a camada mais superficial, pela maior proximidade com a serapilheira. A estabilidade do solo foi alta para todos os tratamentos que apresentaram relação $\mathrm{C}: \mathrm{N}$ abaixo de 12:1. Para estimar a forma como a MOS está armazenada foi feito o fracionamento químico pela obtenção de extratos ácidos e alcalinos, que apontou maior produção de ácidos fúlvicos $(\mathrm{AF})$ e húmicos $(\mathrm{AH})$, e huminas $(\mathrm{HU})$ no plantio de várzea, para as três profundidades de solo. $\mathrm{O}$ plantio no morrote apresentou maiores valores para a relação $(\mathrm{AF}+\mathrm{AH}) / \mathrm{HU}$, o que sugere uma menor estabilidade nesse tratamento. Os resultados indicam que os plantios têm alto potencial para restabelecer as taxas de ciclagem de nutrientes e os teores de matéria orgânica do solo no curto prazo, e que as áreas de morrote necessitam de técnicas adicionais para acelerar o desenvolvimento dos plantios.

Palavras-chave: plantios homogêneos; fertilidade do solo; substâncias húmicas.

\section{ABSTRACT}

A project to restore a degraded area must firstly reestablish organic soil matter and nutrient cycling process. In order to evaluate the influence of indigenous tree plantations on changings in soil fertility and organic matter dynamics, an experiment was installed at the Poço das Antas Biological Reserve, an Atlantic Rain Forest remnant of ca. 5,200. Six treatments involved mature forests (F), 8-year-old mixed plantations of indigenous tree species $(\mathrm{P})$, and abandoned pastures $(\mathrm{G})$, at both the flooding $(\mathrm{V})$ and the sloping $(\mathrm{M})$ areas of the Reserve. The experimental design was completely randomized. Soil samples were collected at the layers $0-2.5 \mathrm{~cm} ; 2-5-7.5 \mathrm{~cm}$; and $7.5-20 \mathrm{~cm}$ to evaluate soil $\mathrm{pH}$, and $\mathrm{Al}, \mathrm{Ca}+\mathrm{Mg}, \mathrm{P}, \mathrm{K}, \mathrm{C}$ and $\mathrm{N}$ contents. The PV treatment showed higher values for the exchangeable cátions, C and soil organic matter (SOM) contents, indicating high cycling rates and biological activity. Soil stability was considered to be high in all treatments, since $\mathrm{C}$ : $\mathrm{N}$ ratio was lower than 12:1. Organic matter fragmentation showed a higher amount of fulvic acids (FA), humic acids (HA) and humin (HU) in the PV treatment, for the three soil layers. The plantation on the sloping areas (PM) showed the highest values of (FA+HA)/HU ratio, suggesting a lower stability condition.

1. Parte da Tese de Doutorado do primeiro autor apresentada ao Curso de Pós-Graduação em Agronomia - Ciência do Solo, Universidade Federal do Rural do Rio de Janeiro.

2. Engenheiro Florestal, Pesquisador do Instituto Brasileiro do Meio Ambiente, Praça XV de Novembro 42, Bairro Centro, CEP 20010-010, Rio de Janeiro (RJ). luiz.moraes@ibama gov.br

3. Engenheiro Florestal, Dr., Pesquisador da Embrapa Agrobiologia, BR 465, Km 7, CEP 23891-000 Seropédica (RJ). campello@cnpab.embrapa.br

4. Engenheiro Agrônomo, Dr., Professor Associado I do Departamento de Solos, Universidade Federal do Rural do Rio de Janeiro, BR 465, Km 7, CEP 23890-000, Seropédica (RJ). gervasio@ufrrj.br

5. Engenheiro Agrônomo, Mestrando do Curso de Pós-Graduação em Agronomia - Ciência do Solo, Universidade Federal do Rural do Rio de Janeiro, BR 465, Km 7, CEP 23890-000, Seropédica (RJ). arcangeloloss@yahoo.com.br

Recebido para publicação em 21/11/2006 e aceito em 25/03/2008. 
Results suggest indigenous tree plantations have great potential to restore nutrient cycling and soil organic matter contents in short term period in areas where forests have been converted into pastures. Techniques to accelerate the development of trees plantation on the sloping areas must be adopted.

Keywords: homogeneous plantings; soil fertility; humic substances.

\section{INTRODUÇÃO}

A restauração de um ecossistema terrestre deve ter como primeira condição um solo saudável, que sustente o estabelecimento de uma comunidade vegetal pelo processo da sucessão secundária. A saúde do solo pode ser definida como a capacidade do solo em manter a produtividade animal e vegetal, manter ou melhorar a qualidade do ar e da água e promover a saúde vegetal e animal (DORAN e ZEISS, 2000).

Geralmente associada a processos erosivos, a degradação do solo pode resultar também na queda de seus níveis de fertilidade, fundamentalmente pela redução nos teores e na qualidade da matéria orgânica e pela redução nos teores dos macro e micronutrientes (GONÇALVES et al., 2003).

As florestas secundárias podem ser fontes (com a formação e decomposição da serapilheira) e sumidouros (com a produção de biomassa) de nutrientes (NAMBIAR, 1984), sendo que, nesse último caso, as perdas variam ao longo da sucessão: são altas no início, decaem nos estágios intermediários e voltam a crescer no final, com uma maior senescência de indivíduos (BROWN e LUGO, 1990; MITCHELL et al., 2000).

Em situações de limitação de nutrientes, as árvores possuem alguns mecanismos para manter taxas de crescimento, como aumentar o acréscimo de nutrientes no solo, maximizar a retenção dos nutrientes no ecossistema e assegurar a conservação e reutilização de elementos pelo indivíduo (Miller, 1984). Esses mecanismos, entretanto, dependem da estrutura da vegetação, e durante o diagnóstico de uma área degradada é fundamental se estimar até que ponto os distúrbios prejudicaram os mecanismos de conservação de nutrientes (MONTAGNINI e JORDAN, 2002).

O diagnóstico do solo em um ambiente que foi submetido a um processo de degradação passa pela avaliação de sua estabilidade. A resistência de um solo pode ser definida então como a capacidade de suportar efeitos dos distúrbios no curto prazo, e a resiliência é a capacidade do solo de se recuperar dos distúrbios (GRIFFITHS et al., 2001).

Não há consenso a respeito dos impactos causados pelo desmatamento sobre os parâmetros de fertilidade do solo. Algumas propriedades químicas melhoram com o desmatamento, como os teores de cátions trocáveis, enquanto outras pioram, como os níveis de matéria orgânica e de nitrogênio (HAUSER et al., 2005).

O papel do nitrogênio na sucessão secundária merece especial atenção pelo seu potencial de perda nos ecossistemas tropicais (GUARIGUATA e OSTERTAG, 2001). Durante a limpeza do solo, o N é perdido sobretudo pela remoção da biomassa, volatilização durante as queimas, denitrificação e lixiviação. Contudo, os níveis de $\mathrm{N}$ no solo podem ser elevados depois do desmatamento, em conseqüência de um aumento na mineralização de $\mathrm{N}$.

A conversão de florestas em pastagens resulta em várias alterações na vegetação e nas propriedades do solo. Em países africanos onde florestas tropicais foram transformadas em savanas, a deficiência de nutrientes é um problema mais sério do que a diminuição das chuvas (BADEJO, 1998). Em áreas onde a floresta é removida, a perda da matéria orgânica do solo (MOS) pode ser particularmente prejudicial (SRIVASTAVA e SINGH, 1991), uma vez que ela tem a função de estabilizar os agregados do solo, aumentar a capacidade de retenção de água do solo e servir como fonte de energia para os decompositores no solo (GUARIGUATA e OSTERTAG, 2001). A MOS também influencia a fertilidade do solo por reter formas orgânicas de nutrientes e ter alta capacidade de trocas de cátions.

Um outro impacto na MOS, muito comum nas áreas de pastagens no domínio da Mata Atlântica, é a ocorrência freqüente de incêndios, cujos produtos são formas químicas de $\mathrm{C}$ altamente resistentes à oxidação e degradação biológica (GONZÁLEZ-PÉREZ et al., 2004).

A matéria orgânica do solo é produto da acumulação de resíduos vegetais e animais parcialmente decompostos e sintetizados, em diversos estágios de complexidade (SILVA e RESCK, 1997; BAYER e 
MIELNICZUK, 1999). A formação da MOS, por sua vez, é função do clima, da vegetação, do material de origem do solo, da topografia e do tempo.

De acordo com sua densidade, a MOS pode ser dividida nas frações leve e pesada. Na fração pesada, encontram-se as substâncias húmicas (SH), que são colóides orgânicos de cor escura. Bioquimicamente, são caracterizadas como moléculas complexas, heterogêneas, modificadas química e biologicamente por condensação e polimerização, de composição variável e alto peso molecular (GUERRA e SANTOS, 1999).

As substâncias húmicas interferem nas propriedades químicas, físicas e biológicas de águas, solos e sedimentos, sendo importantes reservatórios de $\mathrm{C}$ e nutrientes para a vegetação (MANGRICH, 2001). A dinâmica da matéria orgânica no sistema solo-planta, desde sua produção (biomassa vegetal) até sua decomposição e a conseqüente liberação de nutrientes para as plantas, confere sustentabilidade ao sistema.

As substâncias húmicas presentes no solo podem ser divididas, por sua vez, em diferentes frações, de acordo com as características específicas de cada grupo em função dos procedimentos de extração e separação (GUERRA e SANTOS, 1999). Baseado na solubilidade das frações, as substâncias húmicas podem ser divididas em: a) Ácido fúlvico - solúvel em meio ácido e básico; b) Ácido húmico - solúvel em meio básico; e c) Humina - insolúvel.

Pelo fato de muita matéria orgânica ser produzida e decomposta durante os primeiros 20 anos do desenvolvimento da floresta, e o armazenamento aumentar rapidamente naquele tipo de vegetação, sugere-se que o impacto das florestas secundárias na matéria orgânica e na fertilidade do solo é mais intenso durante esse período e diminui proporcionalmente com o tempo (BROWN e LUGO, 1990).

Uma das questões de importância fundamental é a relação entre nutrientes e MOS. O restabelecimento dos níveis de $\mathrm{C}$ no ecossistema durante o processo sucessional é inicialmente limitado pelos teores de $\mathrm{N}$, mas conforme o avanço da sucessão em ambientes tropicais o nutriente limitante passa a ser o $\mathrm{P}$, em razão do intenso intemperismo do solo nesses ambientes (HERBERT et al., 2003). A deficiência de P, por sua vez, limita o acúmulo de $\mathrm{N}$, uma vez que as plantas dependentes de $\mathrm{N}$ simbiótico têm uma alta demanda por P (FRANCO e FARIA, 1997). A estocagem de nutrientes na MOS é importante para conferir resiliência ao ecossistema.

A recomposição dos teores de matéria orgânica do solo é uma primeira e importante meta a se buscar na restauração ecológica. O plantio de espécies arbóreas é uma técnica para aliar adição de matéria orgânica com o desenvolvimento da sucessão secundária, e assim restaurar a fertilidade do solo em áreas degradadas (PARROTTA, 1992). Plantios baseados em modelos sucessionais podem elevar o armazenamento de $\mathrm{C}$ e $\mathrm{N}$ e a taxa de ciclagem de nutrientes, aumentando a eficiência no aproveitamento desses nutrientes pela capacidade diferenciada das espécies em explorar diferentes camadas do solo (HÜTTL e SCHNEIDER, 1998; POGGIANI e SCHUMACHER, 2000; GONÇALVES et al., 2003).

A resiliência da ciclagem de nutrientes nos ecossistemas é fundamental para o sucesso da restauração (MITCHELL et al., 2000). Com alta resiliência, os nutrientes acrescidos ao solo durante o processo de formação da serapilheira nos primeiros anos de sucessão, ou após um plantio, permanecem no sistema e aumentam a probabilidade desse sistema progredir para estágios sucessionais mais avançados.

A restauração de áreas degradadas depende, finalmente, de melhorias na fertilidade do solo e no aumento da diversidade vegetal (FANG e PENG, 1997). Nesse sentido, o presente estudo objetivou determinar as alterações nos parâmetros químicos e no teor de matéria orgânica do solo em áreas de floresta madura, plantio de espécies arbóreas nativas e pastagem abandonada, em situações de várzea e morrote, na Reserva Biológica de Poço das Antas.

\section{MATERIAL E MÉTODOS}

As áreas experimentais estão localizadas na Reserva Biológica de Poço das Antas, situada na zona costeira ou região das baixadas litorâneas do estado do Rio de Janeiro, no município de Silva Jardim, entre os paralelos de $22^{\circ} 30^{\prime}$ e $22^{\circ} 33^{\prime} \mathrm{S}$ e os meridianos de $42^{\circ} 15^{\prime}$ e $42^{\circ} 19^{\prime} \mathrm{W}$, em área coberta por trechos de Floresta Ombrófila Densa Aluvial e Floresta Ombrófila Densa Submontana (VELOSO et al., 1991). O clima local é quente e úmido (Aw, de acordo com a classificação de Köppen), com uma discreta estação seca no inverno. A precipitação anual média é de $2.120 \mathrm{~mm}$ e a temperatura média anual de $24,6{ }^{\circ} \mathrm{C}$ (série histórica 1987-1996, segundo dados fornecidos pela Associação Mico-Leão-Dourado e pelo Programa Mata Atlântica/JBRJ). 
As duas unidades geomorfológicas mais importantes da Reserva são as várzeas (temporária ou permanentemente inundadas), onde predominam NEOSSOLOS FLÚVICOS, e os morrotes, com altitudes de até 200 m e predominância de ARGISSOLOS.

Por meio de um trabalho de sensoriamento remoto foi elaborado um mapa geomorfológico (TAKIZAWA, 1995) que identificou sete compartimentos geomorfológicos distribuídos em uma área total de 5.160 ha: a) faixa meândrica, que é a porção da planície aluvional ocupada por meandros (ocupando 450,5 ha da área total da reserva); b) várzea interna, representada pelas planícies de inundação de pequena extensão, aparecendo encaixadas entre os morros e morrotes (450,3 ha da área total); c) várzea externa, que são as planícies de inundação de grande extensão que envolvem as cadeias de morros e morrotes da Rebio (1.985,5 ha); d) alvéolos (132,5 ha), secções alargadas de um vale, geralmente entulhadas de sedimentos, que seriam na verdade planícies intermontanas (TAKIZAWA, 1995); e) morrotes baixos (325,3 ha), que são pequenos morros com topo mais arredondado e altitude de até $80 \mathrm{~m}$, onde predominam declividades de 20 a $40 \%$; f) morrotes altos (1.337,3 ha), que são morros de porte médio com altitude entre 80 a $100 \mathrm{~m}$; e g) morros - monte mais elevado, com altitudes entre 100 e $200 \mathrm{~m}$, com declividades de 18 a 56\% (478,5 ha da área total).

Os tratamentos localizados nos morrotes encontram-se sobre encostas com declividade variando entre 20 e 45\%. Assim, considerando as situações geomorfológicas utilizadas e os sistemas estudados, temos os seguintes tratamentos: i) Floresta na várzea (FV), ii) Plantio na várzea (PV), iii) Pastagem abandonada na várzea (GV), iv) Floresta no morrote (FM), v) Plantio no morrote (PM) e vi) Pastagem abandonada no morrote (GM). As áreas de floresta que foram utilizadas como referência neste estudo (FV e FM) são matas secundárias com aproximadamente 60-70 anos de idade. A vegetação arbórea nas áreas inundáveis (várzeas) apresenta-se com pequeno porte, com o dossel encontrando-se entre 15 e $18 \mathrm{~m}$ de altura; para a floresta de morrote, o dossel chegou a alcançar $30 \mathrm{~m}$. Os índices de diversidade H' encontrados foram 3,985 nats/inds. $(\mathrm{J}=0,871)$ para a floresta inundável e $\mathrm{H}^{\prime}=4,549$ nats/inds. $(\mathrm{J}=0,887)$ para a floresta sobre morros (GUEDES- BRUNI, 1998). A floresta de várzea se encontra sobre um PLANOSSOLO, com textura do horizonte superficial de arenosa a média, e a floresta de morrote sobre um ARGISSOLO de textura argilosa. Os dois plantios experimentais (PV e PM) foram feitos com espaçamento 2,0 $\mathrm{m}$ x 2,0 m, implicando em uma densidade de 2.500 mudas/ha, sendo as espécies empregadas divididas em grupos ecológicas (Tabela 1). O preparo da área incluiu a eliminação mecanizada (uma aração e uma gradagem) da vegetação invasora, com mono dominância de Panicum maximum Jacq. (capim-colonião). Nenhum tipo de fertilização foi utilizado. No plantio de várzea, praticamente não houve mortalidade das mudas plantadas (taxa de sobrevivência de 98\%), mas, no plantio de morrote, a taxa de mortalidade foi de $31 \%$. Essas taxas foram medidas 5 anos após os plantios. O plantio, na várzea, se encontra sobre uma associação de GLEISSOLOS e NEOSSOLOS FLÚVICOS, e o do morrote, sobre um ARGISSOLO .

Como uma das principais metas dos plantios é a de inibir o desenvolvimento das gramíneas pelo seu sombreamento, o modelo prevê que, pelo menos, $50 \%$ das mudas sejam espécies de rápido crescimento (pioneiras e secundárias iniciais), que promoveriam condições para o desenvolvimento das espécies de estágios sucessionais tardios.

As áreas cobertas por gramíneas ( $\mathrm{GV}$ e $\mathrm{GM}$ ) caracterizam pastagens abandonadas há aproximadamente 30-35 anos, segundo relatos de moradores locais, desde a criação da Reserva Biológica de Poço das Antas (Decreto de Criação 73.791, de 03/11/1974). Na situação de várzea, foi escolhida uma área com predominância de capim-colonião, com a presença de alguns indivíduos isolados de Cecropia sp.; para a situação de morrote foi escolhida uma área coberta majoritariamente por capim-gordura, com alguns indivíduos isolados de Cecropia sp., sendo que, no terço inferior da encosta, existe ainda um agrupamento de quatro indivíduos adultos de aroeirinha (Schinus terebenthifolius Raddi). A presença dos indivíduos arbóreos, conforme registrado acima, não interfere, no entanto, na dominância das respectivas espécies herbáceas invasoras. A pastagem na várzea se encontra sobre um GLEISSOLO, e a do morrote, sobre um ARGISSOLO, ambos com textura argilosa.

Pelo fato das áreas estarem em condições homogêneas (mesmo tipo de solo, mesma cobertura vegetal e mesmo uso do solo) há pelo menos 30 anos, foram coletadas três amostras compostas por área, para as profundidades de $0-2,5 \mathrm{~cm} ; 2,5-7,5 \mathrm{~cm}$ e $7,5-20,0 \mathrm{~cm}$, para a quantificação do carbono orgânico. Para a 
avaliação da fertilidade do solo foram coletadas três amostras compostas por área na profundidade de $0-20$ $\mathrm{cm}$.

TABELA 1: Espécies utilizadas em plantios experimentais na Reserva Biológica de Poço das Antas, Rio de Janeiro, com os respectivos tipos de dispersão de frutos e grupos ecológicos.

TABLE 1: Species used in experimental plantations at Reserva Biológica de Poço das Antas, Rio de Janeiro, with the respective types of dispersion of fruits and ecological group.

\begin{tabular}{|c|c|c|c|}
\hline Espécie & Família & Dispersão & GE \\
\hline Plantio na várzea $(\mathrm{PV})$ & Área: 0,84ha & \multicolumn{2}{|c|}{ Época de plantio: Maio/1996 } \\
\hline Citharexylum myrianthum Cham. & Verbenaceae & Zoocórica/barocórica & $\mathrm{P}$ \\
\hline Margaritaria nobilis L.f. & Phyllanthaceae & Zoocórica/barocórica & $\mathrm{P}$ \\
\hline Mimosa bimucronata (DC.) O. Kuntze & Fabaceae & Anemocórica/barocórica & $\mathrm{P}$ \\
\hline Inga affinis DC. & Fabaceae & Zoocórica/hidrocórica & I \\
\hline Inga laurina (Sw.) Willd. & Fabaceae & Zoocórica/hidrocórica & I \\
\hline Pseudobombax grandiflorum (Cav.) A.Robyns & Malvaceae & Anemocórica & I \\
\hline Guarea guidonia (L.) Sleumer & Meliaceae & Zoocórica & $\mathrm{T}$ \\
\hline Jacaratia spinosa (Aubl.) A.DC. & Caricaceae & Zoocórica & $\mathrm{T}$ \\
\hline Calophyllum brasiliense Cambess. & Clusiaceae & Zoocórica/hidrocórica & $\mathrm{C}$ \\
\hline Copaifera langsdorffii Desf. & Fabaceae & Zoocórica & $\mathrm{C}$ \\
\hline Plantio em Morrote (PM) & Área: $0,85 \mathrm{ha}$ & \multicolumn{2}{|c|}{ Época de plantio: Janeiro/1995 } \\
\hline Aegiphila sellowiana Cham. & Lamiaceae & Zoocórica/barocórica & $\mathrm{P}$ \\
\hline Gochnatia polymorpha (Less.) Cabrera & Asteraceae & Anemocórica & $\mathrm{P}$ \\
\hline Piptadenia gonoacantha (Mart.) J. f. Macbr. & Fabaceae & Barocórica & I \\
\hline Piptadenia paniculata. Benth. & Fabaceae & Barocórica & I \\
\hline Sparattosperma leucanthum (Vell.) K.Schum. & Bignoniaceae & Anemocórica & I \\
\hline Centrolobium tomentosum Guillemin ex Benth. & Fabaceae & Barocórica & $\mathrm{T}$ \\
\hline Tabebuia chrysotricha (Mart. ex DC.) Standl. & Bignoniaceae & Anemocórica & $\mathrm{T}$ \\
\hline Cupania racemosa (Vell.) Radlk. & Sapindaceae & Zoocórica/barocórica & $\mathrm{C}$ \\
\hline Nectandra oppositifolia Nees \& Mart. & Lauraceae & Zoocórica/barocórica & $\mathrm{C}$ \\
\hline Virola oleifera (Schott) A.C.Sm. & Myristicaceae & Zoocórica & $\mathrm{C}$ \\
\hline
\end{tabular}

Em que: $\mathrm{GE}$ = grupo ecológico; $\mathrm{P}$ = pioneira; $\mathrm{I}$ = secundária inicial; $\mathrm{T}$ = secundária tardia; $\mathrm{C}=$ clímax.

Para a caracterização da matéria orgânica do solo (MOS) foi adotado o procedimento de extração sugerido pela IHSS (SWIFT, 1996) e adaptado por Benites et al. (2003). Pesou-se uma massa de solo igual a $1,0 \mathrm{~g}$, submetendo-se ao contato com $20 \mathrm{ml}$ de NaOH 0,1 mol L-1 por 24 horas. A separação entre o extrato alcalino $(\mathrm{EA}=\mathrm{AF}+\mathrm{AH})$ e o resíduo foi feita por centrifugação a $5000 \mathrm{~g}$ por 30 minutos. Seguiu-se mais uma lavagem com a mesma solução anterior, juntando-se o extrato com o anteriormente obtido, resultando em volume final de aproximadamente $40 \mathrm{ml}$. O resíduo (humina) foi retirado dos tubos da centrífuga, acondicionados em placa de petri e secado a $65^{\circ} \mathrm{C}$ (secagem completa). $\mathrm{O} \mathrm{pH}$ do extrato alcalino (EA) foi ajustado a $1,0( \pm 0,1)$ com $\mathrm{H}_{2} \mathrm{SO}_{4} 20 \%$, seguido de decantação por 18 horas em geladeira. O precipitado (AH) foi separado da fração solúvel (AF) por filtragem e ambos os volumes aferidos a $50 \mathrm{ml}$, com água destilada. Foram quantificados os teores de carbono orgânico na fração ácidos fúlvicos (AF), fração ácidos húmicos (AH) e humina (HU). Foram calculadas as relações AH/AF, e a relação entre EA/HU (Benites et al., 2003).

A fertilidade do solo foi avaliada pelos seguintes parâmetros: $\mathrm{pH}$ em água (método do potenciômetro), teor de $\mathrm{Al}$ (trocável) e teores de $\mathrm{C}$ (total e orgânico), $\mathrm{N}$ (total), $\mathrm{P}$ (assimilável), $\mathrm{K}, \mathrm{Ca}$ e $\mathrm{Mg}$ (trocáveis). A maior atividade biológica do solo ocorre nos primeiros $20 \mathrm{~cm}$ de solo, onde há maior acúmulo de matéria orgânica, pela formação de serapilheira e pela decomposição das raízes (MOREIRA e SIQUEIRA, 2002). Os métodos de análise de solos foram os adotados pela Embrapa (EMBRAPA, 1997).

O delineamento experimental adotado foi o inteiramente casualizado, com desenho fatorial $3 \times 2 \times 3$ (sistema $\mathrm{x}$ situação $\mathrm{x}$ profundidade do solo) e as médias referentes a cada tratamento foram comparadas pelo Teste de Scott-Knott, com nível mínimo de significância de 5\%; pelo uso do software SISVAR (UFLA Universidade Federal de Lavras). 


\section{RESULTADOS E DISCUSSÃO \\ Fertilidade do Solo}

A caracterização química para a camada superficial de $20 \mathrm{~cm}$ de solo nas áreas estudadas está representada na Tabela 2.

Os solos da área de estudo são, de uma maneira geral, ácidos, sendo que os solos sob floresta madura em várzea apresentaram uma acidez mais acentuada $(\mathrm{p}<0,01)$, provavelmente em razão da textura mais arenosa. $\mathrm{O}$ pH mais elevado observado nas áreas de pastagens abandonadas, para ambas as situações de várzea e morrote, parece estar relacionado aos teores mais elevados de cálcio e magnésio, resultantes da taxa de renovação mais alta para esse tipo de cobertura vegetal, tanto na biomassa aérea quanto no sistema radicular. Os solos sob plantio de várzea apresentaram maior acidez que os solos sob plantio de morrote $(\mathrm{p}<$ $0,01)$, provavelmente por causa da maior produção de ácidos fúlvicos e húmicos no primeiro. Quanto aos valores de $\mathrm{pH}$, estes variaram entre 3,6 e 5,4. Entre os sistemas avaliados, a área de floresta apresentou os menores valores de $\mathrm{pH}$ tanto na várzea quanto no morrote, sendo o maior valor de $\mathrm{pH}$ verificado na área de pastagem para a situação de várzea. A maior acidez do solo torna a decomposição da matéria orgânica mais lenta (SIQUEIRA e MOREIRA, 1997), o que, de certa forma, confere alguma estabilidade ao sistema, sugerindo ainda uma maior instabilidade da MOS nos solos sob pastagens.

TABELA 2: Caracterização química das amostras coletadas nos primeiros $20 \mathrm{~cm}$ de solo em áreas sob floresta madura, plantio de espécies arbóreas nativas e pastagem abandonada, nas situações de várzea e morrote, na Reserva Biológica de Poço das Antas, RJ.

TABLE 2: Chemical characterization of the samples collected in the first $20 \mathrm{~cm}$ of soil under mature forest, plantation of native arboreal species and abandoned pasture, in the flooding and sloping situations, at Reserva Biológica de Poço das Antas, RJ.

\begin{tabular}{|c|c|c|c|c|c|c|c|c|c|c|}
\hline \multirow{3}{*}{ Sistema } & \multirow{2}{*}{\multicolumn{2}{|c|}{ pH (água) }} & \multicolumn{2}{|c|}{$\mathrm{Al}$} & \multicolumn{2}{|c|}{$\mathrm{Ca}+\mathrm{Mg}$} & \multicolumn{2}{|c|}{$\mathrm{P}$} & \multicolumn{2}{|c|}{ K } \\
\hline & & & \multicolumn{4}{|c|}{$\mathrm{cmol}_{\mathrm{c}} / \mathrm{dm}^{3}$} & \multicolumn{4}{|c|}{$\mathrm{mg} / \mathrm{dm}^{3}$} \\
\hline & V & $\mathrm{M}$ & $\mathrm{V}$ & M & $\mathrm{V}$ & $\mathrm{M}$ & V & $\mathrm{M}$ & $\mathrm{V}$ & M \\
\hline Floresta & $3,67 \mathrm{Aa}$ & $4,03 \mathrm{Ba}$ & $1,73 \mathrm{Bc}$ & $1,23 \mathrm{Ab}$ & $0,33 \mathrm{Aa}$ & $0,87 \mathrm{Ba}$ & $4,63 \mathrm{Bb}$ & $1,90 \mathrm{Aa}$ & $28,50 \mathrm{Aa}$ & $30,93 \mathrm{Aa}$ \\
\hline Plantio & $4,37 \mathrm{Ab}$ & $4,83 \mathrm{Bb}$ & $1,67 \mathrm{Bb}$ & $1,00 \mathrm{Ab}$ & $1,23 \mathrm{Ab}$ & $0,87 \mathrm{Aa}$ & $3,47 \mathrm{Ba}$ & $1,37 \mathrm{Aa}$ & $56,87 \mathrm{Bb}$ & $17,40 \mathrm{Aa}$ \\
\hline Pastagem & $5,37 \mathrm{Bc}$ & $5,00 \mathrm{Ab}$ & $0,36 \mathrm{Aa}$ & $0,47 \mathrm{Aa}$ & $2,43 \mathrm{Bc}$ & $1,17 \mathrm{Aa}$ & $2,57 \mathrm{Aa}$ & $1,33 \mathrm{Aa}$ & $82,43 \mathrm{Bc}$ & $20,30 \mathrm{Aa}$ \\
\hline$\overline{C V}(\%)$ & & & & 98 & & 60 & & 33 & & 93 \\
\hline
\end{tabular}

Em que: Valores seguidos pelas mesmas letras minúsculas nas colunas e pelas mesmas letras maiúsculas nas linhas, para cada parâmetro, não diferem estatisticamente, de acordo com o teste de Scott-Knott $(p<0,05)$; Legenda: $\mathrm{V}=$ Várzea; $\mathrm{M}=$ Morrote; $\mathrm{CV}=$ coeficiente de variação.

Os teores de $\mathrm{Al}$ foram maiores para os solos sob a floresta $(\mathrm{p}<0,01)$, e nos solos sob pastagem o Al se encontrou menos disponível. Quando comparadas às situações geomorfológicas, houve diferenças somente para os sistemas floresta $(\mathrm{p}<0,01)$ e plantio $(\mathrm{p}<0,01)$ na área de várzea. $\mathrm{O}$ solo amostrado foi classificado como ARGISSOLO álico (TAKIZAWA, 1995), o que sugere que o Al tem origem pedogenética. Os valores mais baixos de $\mathrm{Ca}+\mathrm{Mg}(\mathrm{p}<0,01)$ foram verificados para os solos sob floresta na área de várzea. Esse comportamento pode ser por esses sistemas terem estrutura mais complexa e composição florística mais diversa, imobilizando mais fortemente esses elementos, que são componentes estruturais dos vegetais. A maior taxa de renovação de biomassa parece ser responsável pelos maiores valores de $\mathrm{Ca}+\mathrm{Mg}$ encontrados nos solos das pastagens abandonadas. Com exceção a área de floresta, os maiores valores desses elementos são observados nas áreas da várzea e estão relacionados a um maior aporte de material orgânico que por posterior decomposição irá liberar maiores quantidades desses nutrientes.

Elemento altamente móvel, os valores mais altos de $\mathrm{K}$ no solo foram registrados para as áreas de pastagens $(\mathrm{p}<0,01)$, seguidas pelas de plantio, mas somente na situação de várzea. Para a situação de morrote não foram observadas diferenças entre os sistemas para os valores de $\mathrm{K}$. Os teores na floresta de morrote foram semelhantes aos de várzea, sendo que para as áreas de plantio com espécies arbóreas e as pastagens abandonadas, maiores valores de $\mathrm{K}$ foram registrados na condição de várzea. Vale lembrar que o $\mathrm{K}$ não é componente das estruturas das plantas, estando preferencialmente ligado a processos metabólicos. Isso faz com que, no processo de liberação dos nutrientes, ele seja um dos primeiros a serem disponibilizados 
para a solução do solo, e confere a esse elemento uma alta taxa de renovação interna ou realocação (MILLER, 1984).

Os dados confirmam a estratégia inicial de ciclagem de nutrientes nas florestas secundárias, de rápido acúmulo de nutrientes na vegetação e rápido retorno pela serapilheira, acompanhado pela rápida renovação e consumo pelas raízes (BROWN e LUGO, 1990; POGGIANI e SCHUMACHER, 2000; GUARIGUATA e OSTERTAG, 2001). Do ponto de vista da sucessão, a ciclagem é caracterizada por uma rápida renovação dos nutrientes durante os estágios iniciais da sucessão, com exceção do $\mathrm{Ca}^{+2}$, e uma mudança para taxas mais lentas de renovação nos estágios mais tardios (MILLER, 1984; GUARIGUATA e OSTERTAG, 2001), como parece o caso das florestas maduras que fazem parte desse estudo.

O uso pretérito do solo também influencia o restabelecimento da fertilidade do solo durante a regeneração da floresta. Florestas secundárias resultantes da regeneração natural em pastagens abandonadas, como é o caso de boa parte dos remanescentes em Poço das Antas, recuperam os teores de carbono do solo mais rapidamente que as florestas originadas da regeneração de campos agrícolas (SILVER et al., 2000).

Todos os solos amostrados nos sistemas e situações estudados são pobres em $\mathrm{P}$, cujos valores estiveram sempre abaixo de $10 \mathrm{mg} / \mathrm{dm}^{3}$. A única diferença observada foi para os solos sob floresta de várzea, de textura mais arenosa que os outros, onde os teores de $\mathrm{P}$ foram maiores que os de morrote. Apesar dos níveis de $\mathrm{P}$ serem baixos não se mostraram limitantes, o que pode significar duas coisas: a) que esse elemento não é limitante para o estabelecimento da sucessão secundária nas florestas de baixada da região, ou b) que todos os sistemas estudados se encontram em estágio sucessional semelhante, e os efeitos adversos da limitação do P surgiriam em estágios mais avançados.

Um parâmetro relacionado à disponibilidade do $\mathrm{P}$ é o teor de MOS. O desaparecimento progressivo de matéria orgânica possibilita a imobilização do P, diminuindo sua disponibilidade para a comunidade vegetal (MONTAGNINI e JORDAN, 2002).

Quando cinco sistemas de ocupação de solo foram avaliados, incluindo o plantio de espécies arbóreas nativas e área em regeneração natural, a análise química mostrou que os níveis de $\mathrm{P}$ se mostraram baixos para todos os sistemas, sugerindo que a sucessão secundária, por si, sem interferência humana, não é suficiente para recuperar os níveis de P no solo (NAGY, 1997).

Comparando um outro plantio misto (aos 3 anos de idade) de espécies arbóreas nativas com duas florestas secundárias (20 e 40 anos de idade), na Reserva Biológica de Poço das Antas, Barbosa (2000) observou que os teores de $\mathrm{N}, \mathrm{C}, \mathrm{K}$ e $\mathrm{Ca}+\mathrm{Mg}$ no solo sob plantio foram semelhantes aos da floresta secundária com 20 anos de idade, que, por sua vez, apresentou níveis significativamente maiores de P. Esses dados sugerem uma maior reciclagem nos primeiros anos de regeneração, relacionada ao período de formação da serapilheira.

Um mecanismo provável para evitar que o $\mathrm{P}$ seja um elemento limitante é o uso de espécies com potencial para a formação de associações micorrízicas: fungos glomaleanos e o $\mathrm{P}$ do solo são fatores importantes na tecnologia de restauração de áreas degradadas (SIQUEIRA et al., 1998).

\section{Matéria Orgânica do Solo}

Os teores de C orgânico, matéria orgânica e $\mathrm{N}$ total do solo são apresentados na Tabela 3, assim como a relação $\mathrm{C} / \mathrm{N}$ no solo.

Não houve diferenças $(p<0,05)$ nos teores de $C$ orgânico do solo entre os três sistemas estudados, na situação de morrote. Na várzea, os valores para o plantio e a pastagem foram superiores aos do solo sob floresta, em razão da alta taxa de renovação de biomassa aérea e de raízes na pastagem e às altas taxas iniciais de crescimento das espécies plantadas, que refletiram positivamente no acúmulo de matéria orgânica por uma maior produção de biomassa vegetal. Dependendo das condições locais e de uso do solo, a conversão de floresta para pastagem pode não significar perda de $\mathrm{C}$ no solo, uma vez que espécies de gramíneas agressivas podem compensar as perdas iniciais com altas taxas de crescimento e rápido acúmulo de C na biomassa (FERNANDES et al., 1997). 
TABELA 3: Teores de C, $\mathrm{N}$ e matéria orgânica nos primeiros $20 \mathrm{~cm}$ de solo para três sistemas - floresta madura, plantio de espécies arbóreas nativas e pastagem abandonada - localizados em várzea e morrote na Reserva de Poço das Antas, RJ.

TABLE 3: $\mathrm{C}, \mathrm{N}$ and organic matter in the first $20 \mathrm{~cm}$ of soil contents for three systems - mature forest, plantation of native arboreal species and abandoned pasture - located in the flooding and sloping situations in the Reserva de Poço das Antas, RJ.

\begin{tabular}{|c|c|c|c|c|c|c|c|c|}
\hline \multirow{3}{*}{ Sistema } & \multicolumn{2}{|c|}{$\mathrm{C}$ org } & \multicolumn{2}{|c|}{ MOS } & \multicolumn{2}{|c|}{ N Total } & \multirow{2}{*}{\multicolumn{2}{|c|}{$\mathrm{C} / \mathrm{N}$ no solo }} \\
\hline & \multicolumn{6}{|c|}{$\mathrm{g} \mathrm{kg}^{-1}$} & & \\
\hline & $\mathrm{V}$ & $\mathrm{M}$ & $\mathrm{V}$ & $\mathrm{M}$ & $\mathrm{V}$ & $M$ & $\mathrm{~V}$ & $\mathrm{M}$ \\
\hline Floresta & $11,5 \mathrm{Aa}$ & $10,9 \mathrm{Aa}$ & $19,5 \mathrm{Aa}$ & $18,9 \mathrm{Aa}$ & $1,0 \mathrm{Ba}$ & $0,13 \mathrm{Ab}$ & $10,7 \mathrm{Bb}$ & $8,7 \mathrm{Aa}$ \\
\hline Plantio & $16,1 \mathrm{Bb}$ & $10,8 \mathrm{Aa}$ & $27,7 \mathrm{Bb}$ & $18,7 \mathrm{Aa}$ & $1,9 \mathrm{Bb}$ & $0,11 \mathrm{Ab}$ & $8,4 \mathrm{Aa}$ & $11,5 \mathrm{Bc}$ \\
\hline Pastagem & $14,7 \mathrm{Bb}$ & $10,8 \mathrm{Aa}$ & $17,0 \mathrm{Aa}$ & $18,5 \mathrm{Aa}$ & $1,6 \mathrm{Bb}$ & $0,08 \mathrm{Aa}$ & $9,11 \mathrm{Aa}$ & $9,8 \mathrm{Bb}$ \\
\hline CV (\%) & 10 & & & 06 & & 06 & & \\
\hline
\end{tabular}

Em que: Valores seguidos pelas mesmas letras minúsculas nas colunas e pelas mesmas letras maiúsculas nas linhas, para cada parâmetro, não diferem estatisticamente, de acordo com o teste de Scott-Knott $(p<0,05)$; Legenda: $V=$ Várzea; $\mathrm{M}=$ Morrote; $\mathrm{CV}=$ coeficiente de variação.

Os valores de $\mathrm{C}$ orgânico foram maiores na situação de várzea, para as três camadas estudadas, o que reforça a sugestão de que o ambiente de várzea é mais eficiente na conservação da matéria orgânica do solo, para as condições da Reserva de Poço das Antas.

Em estudo realizado na região de monções da China tropical, a ausência significativa de espécies de maior porte em áreas degradadas resultou em um teor de $\mathrm{C}$ orgânico muito baixo $(0,2 \%)$, enquanto no solo sob floresta secundária o valor correspondente foi de 1,47\% (MAO et al., 1992), acima da média apresentada pelas florestas maduras nesse estudo $(1,12 \%)$.

Para o nitrogênio total do solo, os teores foram mais altos $(\mathrm{p}<0,01)$ também para a situação de várzea, onde o plantio e a pastagem foram os sistemas com maior teor de $\mathrm{N}$ no solo. A maior ciclagem potencial de nutrientes no plantio e os maiores valores de $C$ orgânico observados para este sistema justificam a maior retenção de N. Quando comparadas as situações geomorfológicas, os valores foram maiores para a situação de várzea $(\mathrm{p}<0,01)$, como observado para os teores de $\mathrm{C}$ orgânico.

Os teores de $\mathrm{N}$ para em todos os sistemas avaliados foram maiores na situação de várzea em comparação com as áreas de morrote $(\mathrm{p}<0,05)$. Entre as áreas os menores teores de $\mathrm{N}$ foram observados para o sistema floresta na situação de várzea, já na situação de morrote a pastagem apresentou os menores valores.

Os valores da relação C:N para as áreas amostradas nesse estudo variaram entre 8,40 e 11,5, sugerindo uma possível condição de estabilidade para os três sistemas investigados - floresta madura, plantio de espécies arbóreas nativas e pastagem abandonada. A relação $\mathrm{C}: \mathrm{N}$ no solo foi maior para a situação de morrote $(\mathrm{p}<0,05)$. Não foram observadas diferenças neste parâmetro entre os sistemas e entre as profundidades $(\mathrm{p}<0,05)$. A relação $\mathrm{C}: \mathrm{N}$ é considerada estabilizada quando seus valores estão situados entre 8:1 e 12:1 (MOREIRA e SIQUEIRA, 2002).

Quando analisada a variação dos valores da relação $\mathrm{C}: \mathrm{N}$ nos sistemas em relação à situação geomorfológica, o único sistema que apresentou valores maiores na várzea do que no morrote foi a floresta, pelo maior teor de $\mathrm{N}$ nesse sistema na referida situação, como apresentado acima. O plantio de espécies arbóreas nativas na área de várzea foi o que apresentou maiores teores (\%) de matéria orgânica no solo (MOS). A Figura 1 apresenta os valores de MOS para as profundidades de 0-2,5 cm, 2,5-7,5 cm e 7,5-20 cm, para os sistemas e situações estudados. 


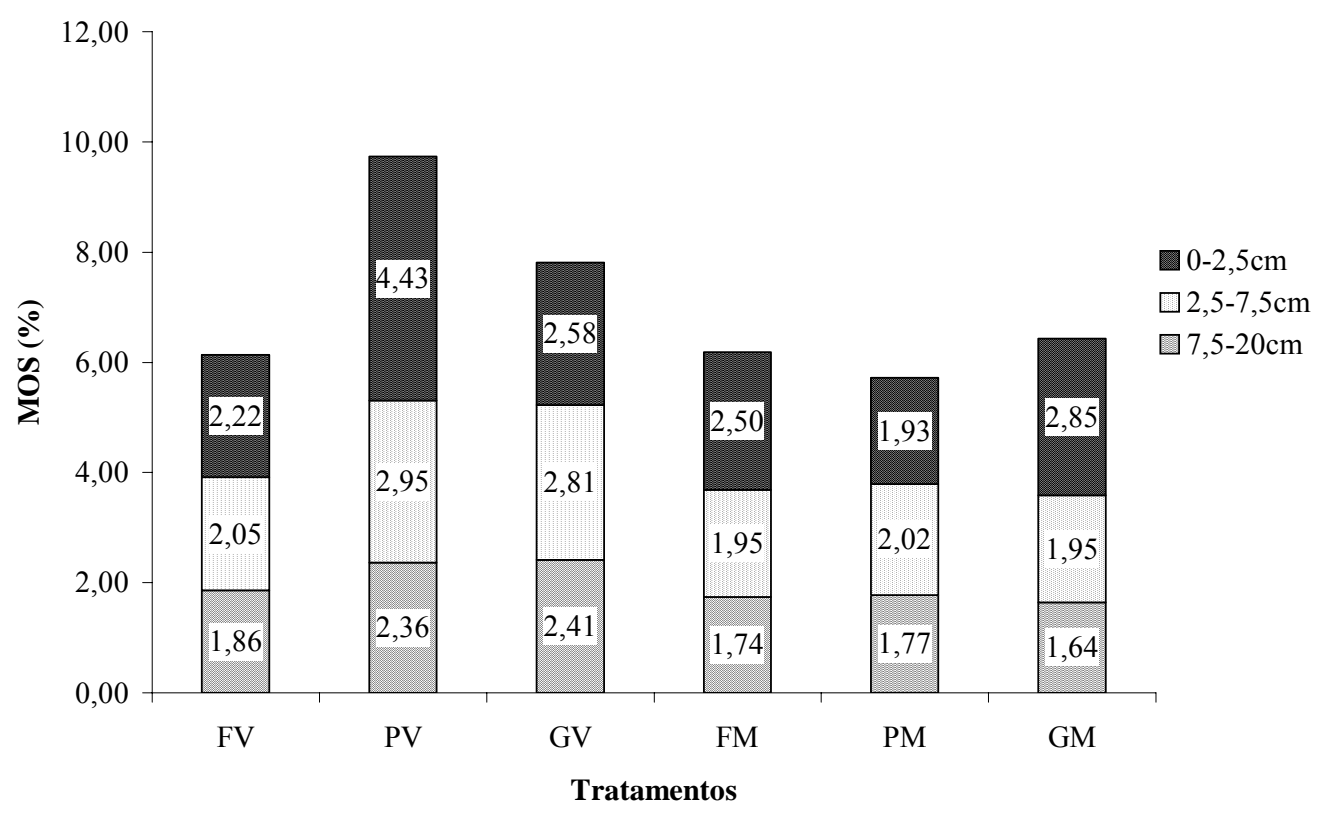

FIGURA 1: Distribuição de MOS - matéria orgânica do solo (\%) nos primeiros $20 \mathrm{~cm}$ de solo em floresta madura $(F)$, plantio de espécies arbóreas nativas $(P)$ e pastagens abandonadas $(\mathrm{G})$, em situações de várzea $(\mathrm{V})$ e morrote $(\mathrm{M})$, na Reserva Biológica de Poço das Antas.

FIGURE 1: Distribution of SOM - organic matter of the soil (\%) in the first $20 \mathrm{~cm}$ of soil in mature forest $(\mathrm{F})$, plantation of native arboreal species $(\mathrm{P})$ and abandoned pastures $(\mathrm{G})$, in flooding $(\mathrm{V})$ and sloping (M), situations at Reserva Biológica de Poço das Antas, RJ.

A produtividade de um sistema a longo prazo é bastante dependente do acúmulo de matéria orgânica, que evita a fixação do $\mathrm{P}$ e favorece a formação de um reservatório de $\mathrm{P}$ orgânico (FRANCO e FARIA, 1997). Os plantios de várzea, portanto, têm maior disponibilidade potencial de $\mathrm{P}$.

Os altos valores de MOS nos plantios $(\mathrm{p}<0,01)$ indicam que o plantio de espécies arbóreas é eficiente em um primeiro aspecto da restauração, que é o aumento da qualidade do solo para que o processo sucessional tenha condições de se estabelecer. A MOS, além de ser fonte de C orgânico de alta disponibilidade, confere ao sistema outras vantagens, como uma maior capacidade de reter nutrientes, maior capacidade de reter água e de imobilizar elementos que podem ter algum grau de toxicidade. Por permitir essa série de inferências, a MOS se apresenta como um excelente indicador de restauração.

A situação de várzea apresentou uma maior porcentagem de MOS para os sistemas de plantio ( $\mathrm{p}<$ $0,01)$ e pastagem abandonada $(\mathrm{p}<0,01)$. Por ser uma área com alto teor de umidade no solo, a atividade biológica nessa situação é estimulada, aumentando a decomposição dos resíduos orgânicos (MOREIRA e SIQUEIRA, 2002).

Embora os baixos teores de MOS sejam menos limitantes para o restabelecimento da vegetação que a baixa disponibilidade de $\mathrm{N}$ e $\mathrm{P}$, a MOS é muito importante para manter a ciclagem de nutrientes, o estabelecimento e a manutenção das características físicas do solo (MUMMEY et al., 2002). A remoção da vegetação pode induzir a uma redução da contribuição de fungos na composição da comunidade microbiana, levando a uma diminuição da relação $\mathrm{C}$ : $\mathrm{N}$ da $\mathrm{MOS}$ e a uma modificação no seu padrão de decomposição (HENROT e ROBERTSON, 1994).

A ação da matéria orgânica pode mesmo ser considerada a principal responsável pelo sucesso da revegetação (PARROTTA et al., 1997). Nesse contexto, as áreas degradadas que ocupam a Reserva Biológica de Poço das Antas (pastagens abandonadas) e que foram avaliados neste estudo têm grandes chances de serem restaurados.

O fracionamento da matéria orgânica mostra uma maior proporção de huminas em relação às formas menos estáveis nos três sistemas estudados, seja nas áreas de várzea, ou de morrote (Figura 2). Huminas são 
ácidos orgânicos de cadeia longa, formados em condições de maior estabilidade, em que a decomposição da matéria orgânica do solo é mais lenta.

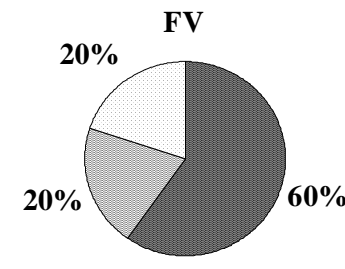

FM

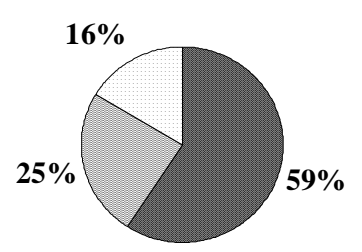

Huminas

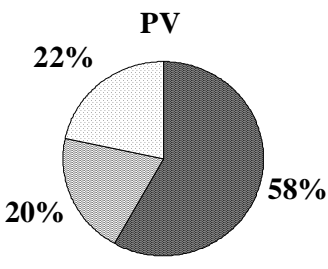

PM

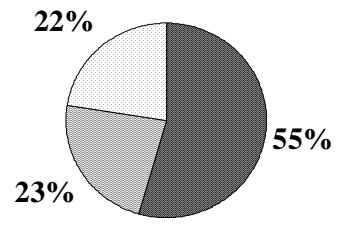

Ácidos Húmicos
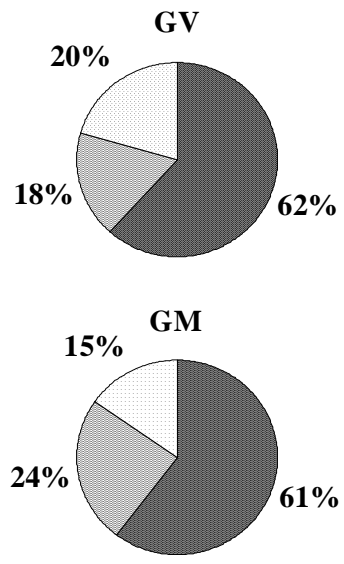

Ácidos Fúlvicos

FIGURA 2: Distribuição dos ácidos orgânicos (\%) em solos na Reserva de Poço das Antas, nos sistemas floresta madura $(F)$, plantios de espécies arbóreas nativas $(P)$ e pastagens abandonadas $(\mathrm{G})$, para as situações de várzea $(\mathrm{V})$ e morrote $(\mathrm{M})$.

FIGURE 2: Soil organic acids distribution (\%) at Reserva de Poço das Antas, in the systems mature forest $(\mathrm{F})$, plantation of native arboreal species $(\mathrm{P})$ and abandoned pastures $(\mathrm{G})$, for the flooding $(\mathrm{V})$ and sloping $(\mathrm{M})$ situations.

Os teores individualizados para cada substância húmica são apresentados na Tabela 4.

TABELA 4: Fracionamento químico da matéria orgânica do solo (MOS) nos primeiros $20 \mathrm{~cm}$ de solo sob floresta madura (Floresta), plantios de espécies arbóreas nativas (Plantio) e pastagens abandonadas (Pastagem), na Reserva Biológica de Poço das Antas, RJ.

TABLE 4: Organic matter of the soil (SOM) chemical fractioning in the first $20 \mathrm{~cm}$ of soil under mature forest ripens (Forest), plantation of native arboreal species (Plantation) and abandoned pastures (Pasture), at Reserva Biológica de Poço das Antas, RJ.

\begin{tabular}{|c|c|c|c|c|c|c|}
\hline \multirow{3}{*}{ Sistemas } & \multicolumn{2}{|c|}{ Ácidos Fúlvicos } & \multicolumn{2}{|c|}{ Ácidos Húmicos } & \multicolumn{2}{|c|}{ Humina } \\
\hline & \multicolumn{6}{|c|}{$\mathrm{g} / 100 \mathrm{~g}$} \\
\hline & $\mathrm{V}$ & $\mathrm{M}$ & $\mathrm{V}$ & $\mathrm{M}$ & $\mathrm{V}$ & M \\
\hline Floresta & $0,28 \mathrm{Aa}$ & $0,31 \mathrm{Aa}$ & $0,26 \mathrm{Aa}$ & $0,19 \mathrm{Aa}$ & $0,81 \mathrm{Aa}$ & $0,72 \mathrm{Aa}$ \\
\hline Plantio & $0,40 \mathrm{Ba}$ & $0,28 \mathrm{Aa}$ & $0,36 \mathrm{Bb}$ & $0,24 \mathrm{Aa}$ & $1,03 \mathrm{Bb}$ & $0,67 \mathrm{Aa}$ \\
\hline Pastagem & $0,31 \mathrm{Aa}$ & $0,31 \mathrm{Aa}$ & $0,35 \mathrm{Bb}$ & $0,22 \mathrm{Aa}$ & $1,07 \mathrm{Bb}$ & $0,82 \mathrm{Ab}$ \\
\hline $\mathrm{CV}(\%)$ & \multicolumn{2}{|c|}{17,04} & \multicolumn{2}{|c|}{16,24} & \multicolumn{2}{|c|}{6,51} \\
\hline
\end{tabular}

Em que: Valores seguidos pelas mesmas letras minúsculas nas colunas e pelas mesmas letras maiúsculas nas linhas, para cada parâmetro, não diferem estatisticamente, de acordo com o teste de Scott-Knot $(\mathrm{p}<0,05)$; Legenda: $\mathrm{V}=$ Várzea; $\mathrm{M}=$ Morrote; $\mathrm{CV}$ = coeficiente de variação.

Quando consideradas somente as situações morfológicas, a várzea apresentou teores maiores para as três formas de substâncias húmicas $(\mathrm{p}<0,01)$, da mesma forma que os plantios em relação aos outros sistemas, exceto para huminas, quando os teores nas pastagens foram similares aos dos plantios. A análise dos sistemas em relação às situações indica que na várzea ocorrem os maiores teores de ácidos fúlvicos (AF), ácidos húmicos $(\mathrm{AH})$ e huminas $(\mathrm{HU})$, sugerindo que o processo de humificação da matéria orgânica é bastante expressivo. Isso confirma que os plantios nas áreas de várzea podem restabelecer, no curto prazo, a estabilidade dessas áreas degradadas na Reserva de Poço das Antas. Por outro lado, os plantios nos morrotes devem adicionar técnicas que acelerem a deposição e a transformação da matéria orgânica, como o uso de espécies fixadoras de nitrogênio atmosférico ou que desenvolvam relações micorrízicas. 
Tão importante quanto conhecer o teor de MOS é identificar em quais formas químicas ela está armazenada. Substâncias húmicas se encontram quase estáticas, com um tempo de reciclagem muito baixo, representando um estoque passivo de C no solo (MOREIRA e SIQUEIRA, 2002). Por apresentar uma maior produção de substâncias húmicas totais, o plantio de várzea possui uma maior estabilidade que os outros tratamentos, o que reforça o potencial dessa ação na restauração do ecossistema (FIGURA 3). Em situações de estresse nutricional, a estrutura alifática dos ácidos húmicos aparenta ser bastante útil para os microorganismos do solo (FILIP e KUBÁT, 2003).

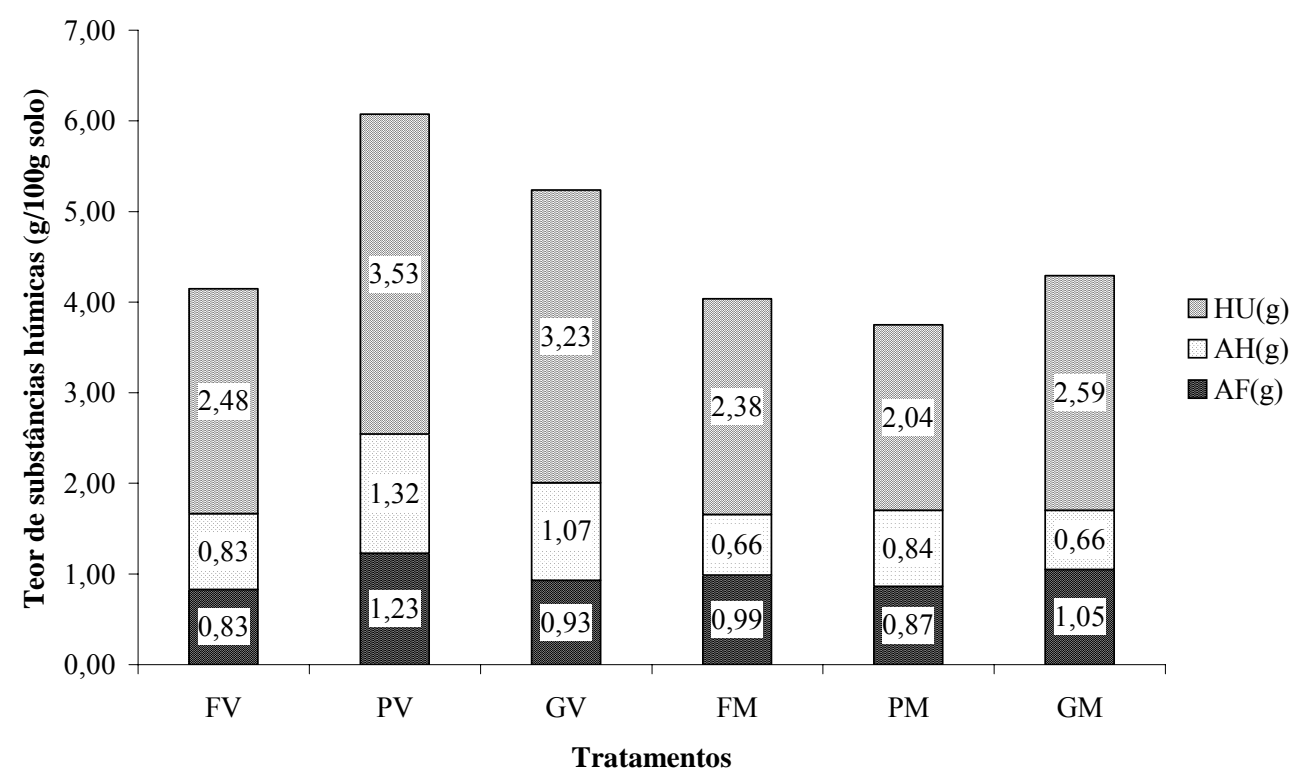

FIGURA 3: Distribuição quantitativa de substâncias húmicas nos primeiros $20 \mathrm{~cm}$ do solo nos sistemas floresta madura (F), plantio de espécies arbóreas nativas $(P)$ e pastagens $(\mathrm{G})$ abandonadas na Reserva Biológica de Poço das Antas, para as situações de morrote $(\mathrm{M})$ e várzea $(\mathrm{V})$. Legenda: $\mathrm{HU}=$ humina; $\mathrm{AH}=$ ácidos húmicos; $\mathrm{AF}=$ ácidos fúlvico.

FIGURE 3: Quantitative distribution of humic substances in the first $20 \mathrm{~cm}$ of the soil in the mature forest $(F)$, plantation of native arboreal species $(\mathrm{P})$ and abandoned pastures $(\mathrm{G})$ systems at Reserva Biológica de Poço das Antas, for the sloping situations (M) and flooding (V). Legend: $\mathrm{HU}=$ humin; $\mathrm{AH}=$ humic acids; $\mathrm{AF}=$ fulvic acids.

Para dar uma outra dimensão à análise da condição da estabilidade da MOS nos sistemas e situações estudadas foram estabelecidas relações entre as formas menos e as mais humificadas das substâncias húmicas (Tabela 5). Os valores para a relação $\mathrm{AH}$ :AF foram menores para a situação de morrote, para as áreas de pastagem e floresta, quando esses fatores de variação foram analisados individualmente. Na análise de cada sistema nas situações estudadas, o plantio foi o único que não apresentou diferenças entre as situações, o que sugere que a situação de morrote contribui preferencialmente para menores relações AH : AF. Já a relação $(\mathrm{AF}+\mathrm{AH}): \mathrm{HU}$ só foi diferente para o plantio em morrote, que apresentou valores maiores que os outros tratamentos. 
TABELA 5: Relações entre formas das substâncias húmicas nos primeiros $20 \mathrm{~cm}$ de solo sob floresta madura (Floresta), plantio misto de espécies arbóreas nativas (Plantio) e pastagens abandonadas (Pastagem), na Reserva Biológica de Poço das Antas, RJ.

TABLE 5: Relationships among forms of the humic substances in the first $20 \mathrm{~cm}$ of the soil in under mature forest (Forest), mixed plantation of native arboreal species (Planting) and abandoned pastures (Pasture), in the Reserva Biológica de Poço das Antas, RJ.

\begin{tabular}{l|c|c|c|c|}
\hline \multirow{2}{*}{ Sistema } & \multicolumn{2}{|c|}{ Relação AH:AF } & \multicolumn{2}{c}{ Relação (AF+AH):HU } \\
\cline { 2 - 5 } & $\mathrm{V}$ & $\mathrm{M}$ & $\mathrm{V}$ & $\mathrm{M}$ \\
\hline Floresta & $0,94 \mathrm{Ba}$ & $0,60 \mathrm{Aa}$ & $0,60 \mathrm{Aa}$ & $0,69 \mathrm{Aa}$ \\
Plantio & $0,91 \mathrm{Aa}$ & $0,84 \mathrm{Ab}$ & $0,74 \mathrm{Aa}$ & $0,79 \mathrm{Aa}$ \\
Pastagem & $1,11 \mathrm{Aa}$ & $0,65 \mathrm{Aa}$ & $0,63 \mathrm{Aa}$ & $0,71 \mathrm{Aa}$ \\
\hline CV (\%) & \multicolumn{2}{|c|}{20,63} & \multicolumn{2}{|c}{12,53} \\
\hline
\end{tabular}

Em que: Valores seguidos pelas mesmas letras minúsculas nas colunas e pelas mesmas letras maiúsculas nas linhas, para cada parâmetro, não diferem estatisticamente, de acordo com o teste de Scott-Knot $(\mathrm{p}<0,05)$; Legenda: V = Várzea; $\mathrm{M}=$ Morrote; $\mathrm{AH}$ = ácidos húmicos; $\mathrm{AF}$ = ácidos fúlvicos; $\mathrm{HU}=$ huminas; $\mathrm{CV}=$ coeficiente de variação.

A Figura 4 apresenta as relações entre ácidos húmicos e ácidos fúlvicos individualizadas nas camadas de solo utilizadas neste estudo $(0-2,5 \mathrm{~cm} ; 2-5-7,5 \mathrm{~cm} ; 7,5-20 \mathrm{~cm})$. Valores da relação AH : AF próximos a 1,0 sugerem sistemas mais estáveis (CANELAS, 1999). Estudo na Amazônia apresentou valor 1,0 da relação AH:AF para solos sob floresta madura (ANDREUX et al., 1990). Os valores de AH:AF para ARGISSOLOS, na região de tabuleiros no norte do Estado do Rio de Janeiro, foram de 1,77 para floresta madura e de 3,04 para pastagem (FONTANA et al., 2001).

Sob condições naturais, a síntese de substâncias húmicas é bastante dependente de fontes fenólicas, liberadas de resíduos vegetais por atividade microbiana, oxidadas e polimerizadas. Em regiões onde há sazonalidade, os períodos úmidos são mais favoráveis à liberação de compostos fenólicos (ANDREUX et al., 1990), mas esse parece não ser o caso de Poço das Antas.

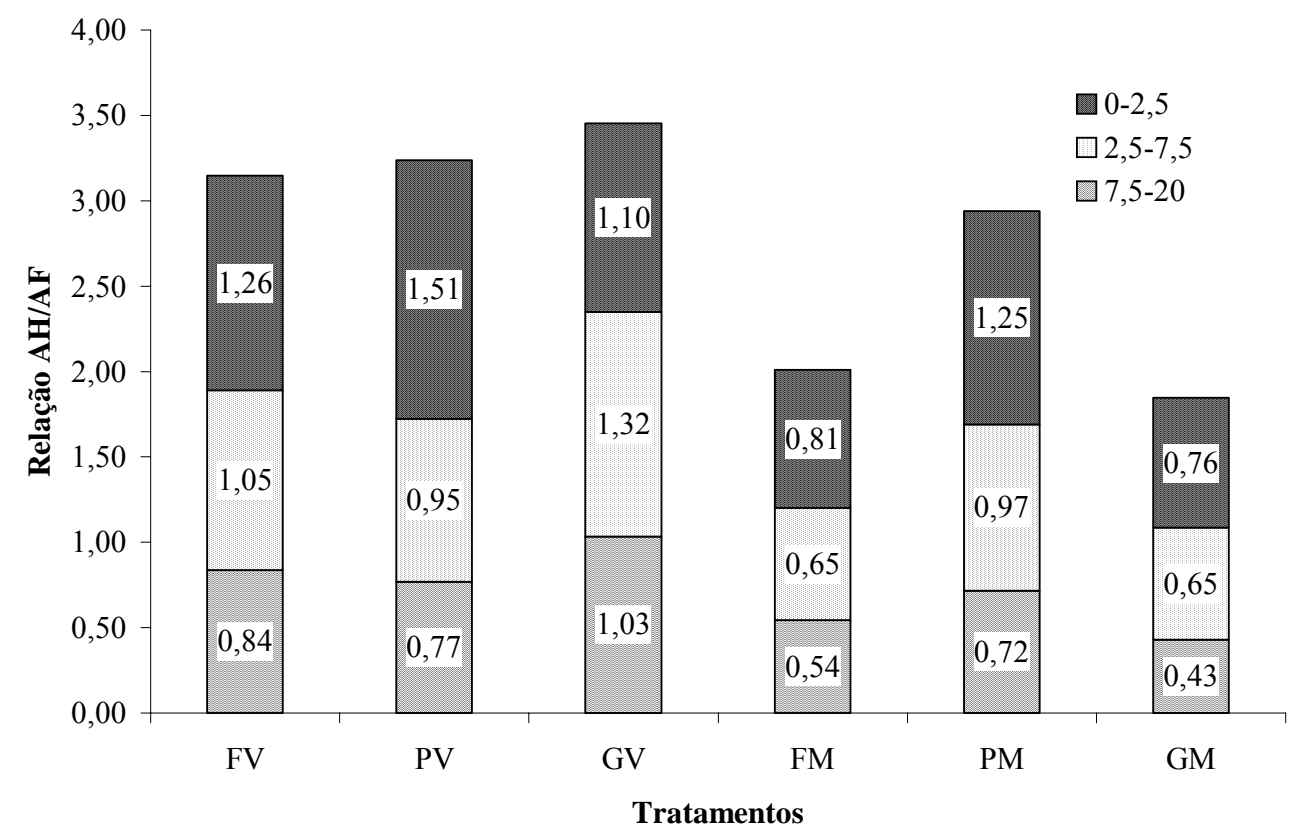

FIGURA 4: Relação entre Ácidos Húmicos (AH) e Ácidos Fúlvicos (AF) nos primeiros $20 \mathrm{~cm}$ de solo nos sistemas floresta madura (F), plantio de espécies arbóreas nativas $(\mathrm{P})$ e pastagens abandonadas (G) na Reserva Biológica de Poço das Antas, para as situações de morrote (M) e várzea (V).

FIGURE 4: Relationship among humic acids (AH) and fulvic acids $\mathrm{s}(\mathrm{AF})$ in the first $20 \mathrm{~cm}$ the mature forest $(\mathrm{F})$, plantation of native arboreal species $(\mathrm{P})$ and abandoned pastures $(\mathrm{G})$ systems in the Reserva Biológica de Poço das Antas, for the sloping (M) and and floding (V) situations. 


\section{CONCLUSÕES}

Os plantios mistos de espécies arbóreas nativas conseguiram atingir níveis de fertilidade do solo semelhantes aos de floresta madura na Reserva Biológica de Poço das Antas. Os níveis de P foram baixos para todos os sistemas estudados, em ambas as situações, mas não se mostraram limitantes.

O restabelecimento dos níveis de MOS pelos plantios na área de várzea é um importante passo para a garantia do sucesso desse método na restauração de áreas degradadas na Reserva de Poço das Antas e nos ecossistemas similares. O plantio de morrote foi menos eficiente no armazenamento de matéria orgânica no solo, apresentando também o maior valor para a relação C:N no solo.

A maior proporção de substâncias húmicas de alto peso molecular (huminas) sugere que os três sistemas estudados estão estabelecidos em solos com um bom grau de estabilidade, sendo que a degradação está expressa basicamente na redução da diversidade vegetal. Os maiores teores de substâncias húmicas apresentados pelos plantios indicam que esse método tem alto potencial para restaurar as áreas degradadas na Reserva de Poço das Antas, em especial na situação de várzea.

\section{REFERÊNCIAS BIBLIOGRÁFICAS}

ANDREUX, F.G.; CERRI, C.C.; EDUARDO, B. de P.; CHONÉ, T. Humus content and transformations in native and cultivated soils. The Science of the Total Environment, v. 90, p. 249-265, 1990.

BADEJO, M.A. Agroecological restoration of savanna ecosystems. Ecological Engineering, v.10, p. 209-219, 1998.

BARBOSA, J.H.C. Dinâmica da serapilheira em estágios sucessionais da Floresta Atlântica (Reserva Biológica de Poço das Antas-RJ). 2000. 195f. Dissertação (Mestrado em Agronomia - Ciência do Solo) - Universidade Federal Rural do Rio de Janeiro, Seropédica, 2000.

BAYER, C.; MIELNICZUK, J. Dinâmica e função da matéria orgânica. In: SANTOS, G.A. e Camargo, F.A.O. Fundamentos da matéria orgânica do solo. Porto Alegre: Genesis, 1999. 491p.

BENITES, V.M.; MADARI, B.; MACHADO, P.L.O. de A. Extração e Fracionamento Quantitativo de Substâncias Húmicas do Solo: um Procedimento simplificado de Baixo Custo. Rio de Janeiro: Embrapa Solos, 2003. 7 p. (Embrapa Solos. Comunicado Técnico, 16).

BROWN, S.; LUGO, A.E. Tropical secondary forests. Journal of Tropical Ecology, v.6, p. 1-32, 1990.

CANELAS, L.P. Avaliação de características físico-químicas de ácidos húmicos. 1999. 164f. Tese. (Doutorado em Agronomia - Ciência do Solo) - Universidade Federal Rural do Rio de Janeiro, Seropédica, RJ, 1999.

DORAN, J.W.; ZEISS, M.R. Soil health and sustainability: managing the biotic component of soil quality. Applied Soil Ecology, v.15, p. 3-11. 2000.

EMBRAPA. Centro Nacional de Pesquisa de Solos (Rio de Janeiro). Manual de métodos de análise de solo. 2.ed. Rio de Janeiro, 1997. 212p.

FANG, W.; PENG, S.L. Development of species diversity in the restoration process of establishing a tropical manmade forest ecosystem in China. Forest Ecology and Management, v. 99, p. 185-196. 1997.

FERNANDES, E.C.M.; MOTAVALLI, P.P.; CASTILLA, C.; MUKURUMBIRA, L.. Management control of soil organic matter dynamics in tropical land-use system. Geoderma, v. 79, p. 49-67, 1997.

FILIP, Z.; KUBÁT, J. Aerobic short-term utilization and degradation of humic acids extracted from soils of long-term field experiments. European Journal of Soil Biology, v. 39, p.175-182, 2003.

FONTANA, A.; PEREIRA, M.G.; NASCIMENTO, G.B.; ANJOS, L.H.C.; EBELING, A.G. Matéria orgânica em solos de tabuleiros na região Norte Fluminense-RJ. Floresta e Ambiente, v.8, n.1, p: 114-119, 2001.

FRANCO, A.A.; FARIA, S.M. The contribution of $\mathrm{N}_{2}$-fixing tree legumes to land reclamation and sustainability in the tropics. Soil Biology \& Biochemistry, v. 29, n. 5/6, p. 897-903, 1997.

GONÇALVES, J.L.M.; NOGUEIRA Jr., L.R.; DUCATTI, F. Recuperação de solos degradados. In: KAGEYAMA, P.Y.; OLIVEIRA, R.E.; MORAES, L.F.D.; ENGEL, V.L.; GANDARA, F.B. (eds.) Restauração Ecológica de Ecossistemas Naturais. Botucatu: FEPAF, 2003. 340p.

GONZÁLEZ-PÉREZ, J.A.; GONZÁLEZ-VILA, F.J.; ALMENDROS, G.; KNICKER, H. The effect of fire on soil organic matter - a review. Environmental International, v. 30, p. 855-870, 2004.

GRIFFITHS, B.S.; BONKOWSKI, M.; ROY, J.; RITZ, K. Functional stability, substrate utilization and biological indicators of soils following environmental impacts. Applied Soil Ecology, v.16, p. 49-61, 2001.

GUARIGUATA, M.R.; OSTERTAG, R. Neotropical secondary forest succession: changes in structural and functional characteristics. Forest Ecology and Management, v.148, p.185-206, 2001. 
GUEDES-BRUNI, R.R. Composição, estrutura e similaridade florística de dossel em seis unidades fisionômicas de mata Atlântica no Rio de Janeiro. Tese (Doutorado) - Universidade de São Paulo, São Paulo, 1998.

GUERRA, J.G.M.; SANTOS, G.A. Caracterização da matéria orgânica: métodos químicos e físicos. In: SANTOS, G.A.; CAMARGO, F.A.O. Fundamentos da matéria orgânica do solo. Porto Alegre: Genesis, 1999. p. 227-243.

HAUSER, S.; GANG, E.; NORGROVE, L.; BIRANG, A. M. Decomposition of plant material as an indicator of ecosystem disturbance in tropical land use system. Geoderma, v.129, n. 1-2, p. 99-108, 2005.

HENROT, J.; ROBERTSON, G.P. Vegetation removal in two soils of the humid tropics: effect on microbial biomass. Soil Biology \& Biochemistry, v.26, n.1, p. 111-116, 1994.

HERBERT, D.A.; WILLIAMS, M.; RASTETTER, E.B. A model analysis of $\mathrm{N}$ and $\mathrm{P}$ limitation on carbon accumulation in Amazonian secondary forest after alternate land-use abandonment. Biogeochemistry, v. 65, p. 121$150,2003$.

HÜTTL, R.F.; SCHNEIDER, B.U. Forest ecosystem degradation and rehabilitation. Ecological Engineering, v. 10, p. 19-31, 1998.

MANGRICH, A.S. Estruturas químicas de substâncias húmicas: estratégias de pesquisa. In: ENCONTRO BRASILEIRO DE SUBSTÂNCIAS HÚMICAS, 4. 2001, Viçosa: Anais... Viçosa: Ed. da UFV, 2001. 289p.

MAO, D.M.; MIN, W.M.; YU, L.L.; MARTENS, R.; INSAM, H. Effect of afforestation on microbial biomass and activity in soils of tropical China. Soil Biology \& Biochemistry, v. 24, n.9, p. 865-872. 1992.

MILLER, H.G.. Dynamics of nutrient cycling in plantation ecosystems. In: BOWEN, G.D.; NAMBIAR, E.K.S. Nutrition of plantation forests. London, 1984. p.53-78.

MITCHELL, R.J.; AULD, M.H.D.; LE DUC, M.G.; MARRS, R.H. Ecosystem stability and resilience: a review of their relevance for the conservation management of lowland heaths. Perspectives in Plant Ecology, Evolution and Systematics, v.3, n.2, p. 142-160, 2000.

MONTAGNINI, F.; JORDAN, C. Reciclaje de nutrientes. In: Guariguata, M.R. \& Kattan, G.H. Ecología y conservación de bosques neotropicales. Cartago, 2002. p.167-191.

MOREIRA, F.M.S.; SIQUEIRA, J.O. Microbiologia e bioquímica do solo. Lavras: Editora UFLA, 2002. 626p.

MUMMEY, D.L.; STAHL, P.D.; BUYER, J.S. Microbial biomarkers as an indicator of ecosystem recovery following surface mine reclamation. Applied Soil Ecology, v.21, p. 251-259, 2002.

NAGY, S.C.S.. Avaliação de alguns parâmetros químicos e físicos de um solo submetido a vários processos de ocupação e à recomposição de floresta ripária. SIMPÓSIO NACIONAL DE ÁREAS DEGRADADAS, Ouro Preto, 3. 1997. Anais.....Ouro Preto: Ed. UFV, 1997. p. 156-165. 1997.

NAMBIAR, E.K.S. Plantation trees: their scope and a perspective on plantation. In: BOWEN, G.D.; NAMBIAR, E.K.S. Nutrition of plantation forests, London. p. 1-15, 1984

PARROTTA, J.A. The role of plantation forests in rehabilitating degraded tropical ecosystems. Agriculture, ecosystemes \& environment, v.41, p. 115-133, 1992.

POGGIANI, F.; SCHUMACHER, M. Ciclagem de nutrientes em florestas nativas. In: GONÇALVES, J.L.M.; BENEDETTI, V. Nutrição e Fertilização Florestal. Piracicaba, SP: IPEF 2000. 427p.

SILVA, J.E.; RESCK, D.V.S. Matéria orgânica do solo. In: VARGAS, M.A.T.; HUNGRIA, M. (Ed.). Biologia dos solos dos Cerrados. Planaltina, DF: Embrapa-CPAC, 1997. p.467-524.

SILVER, W.L.; OSTERTAG, R.; LUGO, A.E. The potential for carbon sequestration through reforestation of abandoned tropical agriculture and pasture lands. Restoration Ecology, v.8, n.4, p.394-407, 2000.

SIQUEIRA, J.O.; CARNEIRO, M.A.C.; CURI, N.; ROSADO, S.C.S.; DAVIDE, A.C.. Mycorrhizal colonization and mycotrophic growth of native woody species as related to sucessional groups in Southeastern Brazil. Forest Ecology and Management, v.107, p.241-252, 1998.

SRIVASTAVA, S.C.; SINGH, J.S. Microbial C, N and P in dry tropical forest soils: effects of alternate land-uses and nutrient flux. Soil Biology \& Biochemistry, v.23, n.2, p. 117-124, 1991.

SWIFT, R. S. Organic matter characterization. In: SPARKS, D. L.; PAGE, A. L.; HELMKE, P. A.; LOEPPERT, R. H.; SOLTANPOUR, P. N.; TABATABAI, M. A.; JOHNSTON, C. T.; SUMNER, M. E. (Ed.). Methods of soil analysis. Madison: Soil Science Society of America: American Society of Agronomy, p. 1011-1020, 1996.

TAKIZAWA, F. H. Levantamento pedológico e zoneamento ambiental da Reserva Biológica de Poço das Antas. Piracicaba : USP/ESALQ, 1995. 58p. (Relatório Técnico)

VELOSO, H.P.; RANGEL FILHO, A.L.; LIMA, J.C.A. Classificação da vegetação brasileira, adaptada a um sistema universal. Rio de Janeiro: (IBGE) PROJETO RADAMBRASIL, 1991. 123p. 